\title{
SISTEM PENDUKUNG KEPUTUSAN PENERANGAN RUANGAN BERBASIS IOT MENGGUNAKAN PROTOKOL MQTT DAN FUZZY TSUKAMOTO
}

\author{
(Decision Support System for IOT Based Space Lighting using MQTT Protocol \\ and Tsukamoto Fuzzy Logic)
}

\author{
Ahmad Fauzan Hakim*, Wirarama Wedashwara, Ahmad Zafrullah \\ Mardiansyah Dept Informatics Engineering, Mataram University \\ Jl. Majapahit 62, Mataram, Lombok NTB, INDONESIA \\ Email: a.fauzanhakim@gmail.com, wirarama@unram.ac.id, zaf@unram.ac.id
}

\begin{abstract}
The use of lamp is really needed in adding lighting to a room, because natural light cannot cover the entire room. Especially the room that has a large size and has less light ventilation. So that the lighting in the room can be considered according to lighting standard or not. Therefore, a decision supporting system is really needed for room lighting based on the internet of things and uses MQTT protocol Fuzzy Tsukamoto logic method. MQTT protocol used is CLOUDMQTT as place to save data or called broker. CLOUDMQTT has four important instances info which are server, user, password and port. Those four instances info are used to connect application program with the broker. So, the system can do subscribe and publish from broker to the application. For Fuzzy Tsukamoto the combination of rule is built from three membership functions those are light intensity, time and lamp condition. The combination of rule from two variables which are light intensity and time produces 20 combination of rule. Deffuzification of Fuzzy Tsukamoto is obtained by taking center average grades. Based on the test result which has been conducted at the Uniti PSTI Intelligent System Laboratory of Mataram University the result obtained with the highest intensity value 93 lux and the lowest intensity is 42 lux, with result decision is to always turn on the lamp. So the lighting in the room has not been qualified to lighting standard based on SNI lighting. With a standard of 250 lux.
\end{abstract}

Keywords: internet of things, CLOUDMQTT, broker, subscribe and publish, Fuzzy TsukamotoKey words: Internet of Things, CloudMQTT, Broker, Subscribe and Publish, Fuzzy Tsukamoto.

*Penulis Korespondensi

\section{Pendahuluan}

Penggunaan cahaya matahari sebagai sumber cahaya utama dapat mengurangi penggunaan listrik. Namun, ketersediaan sumber cahaya alami yang tidak konstan karena perubahan cuaca dan permasalahan yang berkaitan dengan kedalaman ruang menyebabkan distribusi cahaya yang masuk ke dalam ruangan tidak merata karena tidak semua bagian dalam ruangan terkena sinar matahari. Kondisi penerangan pada kedua keadaan tersebut dapat dikatakan tidak memenuhi standar penerangan, sehingga dibutuhkan peranan cahaya buatan yang bersinergi dengan cahaya alami[1]. Cahaya buatan adalah segala bentuk cahaya yang bersumber dari alat yang diciptakan oleh manusia, seperti lampu pijar, lilin, lampu minyak tanah, dan obor. Cahaya buatan sering secara langsung diartikan atau diasosiasikan dengan cahaya lampu[2].
Penggunaan lampu sangat dibutuhkan dalam menambah penerangan ruangan, karena cahaya alami tidak bisa mencangkup keseluruhan ruangan. Seperti ruangan Laboratorium Sistem Cerdas PSTI Universitas Mataram, terdapat lampu yang tidak menyala atau mati dan jendela sebagai jalan masuknya cahaya dari luar tertutup oleh banner, sehingga pencahayaan dalam ruangan tersebut kurang maksimal. Oleh sebab itu perlu dilakukan kontrol terhadap pencahayaan dalam ruangan Laboratoium Sistem Cerdas dengan menerapkan Internet of Things (IOT) dan protokol MQTT sebagai tempat pertukaran data serta memanfaatkan metode fuzzy Tsukamoto untuk melakukan perhitungan nilai intensitas cahaya dalam ruangan tersebut.

Untuk melihat apakah penerangan pada ruangan Laboratorium Sistem Cerdas sudah sesuai dengan standar penerangan pada SNI Pencahayaan maka diperlukan sistem pendukung keputusan penerangan ruangan berbasis Internet 
of Things dan menggunakan protokol MQTT dan metode logika Fuzzy Tsukamoto. Sistem akan dikembangkan berbasis mobile dengan data yang diproses terpusat dan intensitas cahaya untuk mengukur penerangan pada ruangan. Metode yang akan digunakan pada sistem yaitu logika Fuzzy Tsukamoto. Metode tersebut digunakan untuk menentukan kondisi penerangan yang sesuai dalam ruangan berdasarkan intensitas cahaya dan waktu. Intensitas cahaya dan waktu adalah variabel yang akan direpresentasikan dengan fungsi keanggotaan fuzzy. Untuk mendapatkan data, digunakan sensor yang dapat mengukur tingkat intensitas cahaya dalam ruangan. Sensor tersebut akan mengirimkan data ke Broker melalui Wi-Fi, serta menggunakan Relay 4 module yang dihubungkan dengan perangkat IoT lainnya sehingga dapat diakses secara online dan dapat menyalakan lampu secara otomatis.

Berdasarkan uraian latar belakang di atas, rumusan masalah yang mendasari penelitian ini adalah bagaimana merancang bangun sistem pendukung keputusan penerangan ruangan berbasis IoT dan Metode Tsukamoto, yang dapat digunakan sebagai pertimbangan jarak antara dua buah lampu dan otomatisasi lampu ruangan pada waktu tertentu berdasarkan nilai hasil pemrosesan intensitas cahaya dan waktu.

\section{Tinjauan Pustaka}

Penelitian yang membahas tengtang kendali lampu dengan mini webserver avr menggunakan mikrokontroler AVR yang dihubungkan dengan relay, triac, dimmer, dan ENC28J60 untuk melakukan kendali lampu melalui web. Penerapan IC LAN ENC28J60 pada mikrokontroler AVR dilakukan untuk membuat antarmuka peralatan listrik dan lampu yang dikendalikan oleh mikrokontroler dan membuat webserver dengan mikrokontroler AVR. AVR webserver dihubungkan ke ethernet switch, modem dan router untuk dapat diakses dari luar rumah. Laptop, komputer, handphone yang terhubung internet dapat mengakses AVR webserver ini. Terbukti rangkaian driver relay dapat melakukan tugas dengan baik, dan rangkaian dimmer yang dirancang dapat dikontrol oleh AVR melalui pin PWM[3].

Pada penelitian selanjutnya membahas sistem kontrol lampu berbasis mikrokontroler Atmega32 yang menggunakan rangkaian dimmer dengan optocoupler dan triac, sensor LDR sebagai pendeteksi cahaya dan sensor PIR sebagai pendeteksi keberadaan manusia, bahasa pemrograman menggunakan Bascom-AVR dan beban yang digunakan adalah lampu pijar 60 watt[4].

Penelitian selanjutnya membahas sistem pengaturan ruangan berbasis android yang menggunakan arduino nano sebagai mikrokontroler, sensor LDR, akuator untuk memutar dimmer, LCD nokia 5110, dan Bluetooth. Sistem ini bertujuan untuk menyesuaikan pencahayaan ruangan berdasarkan kondisi cahaya dalam ruangan dan mengatur kebutuhan intensitas cahaya dalam ruangan. Pembangunan perangkat lunak sistem menggunakan arduino uno dan apage inventor 2 untuk membangun aplikasi android. Tingkat akurasi tertinggi dalam proses kalibrasi pembacaan sensor pada sistem pengaturan pencahayaan ruangan terdapat pada ruang tamu dan akurasi terendah terdapat pada toilet[5].

Pada penelitian selanjutnya membahas sistem pengendali lampu secara otomatis yang menggunakan $\mathrm{pc}$ dan berbasis mikrokontroler arduino uno. Sistem ini bertujuan untuk meningkatkan efisiensi penggunaan energi listrik dan meningkatkan efisiensi kerja manusia. Penelitian ini mengunakan website untuk mengendalikan lampu dengan bantuan bahasa pemrograman web PHP dan database MySQL sebagai tempat penyimpanan data. Hasil dari penelitian ini yaitu lampu dapat dikendalikan dengan normal dan dapat dinyalakan atau dimatikan sesuai input dari pengendalian menu berdasarkan penjadwalan tanggal[6].

\section{Metode Penelitian}

\subsection{Diagram Alir Metode Penelitian}




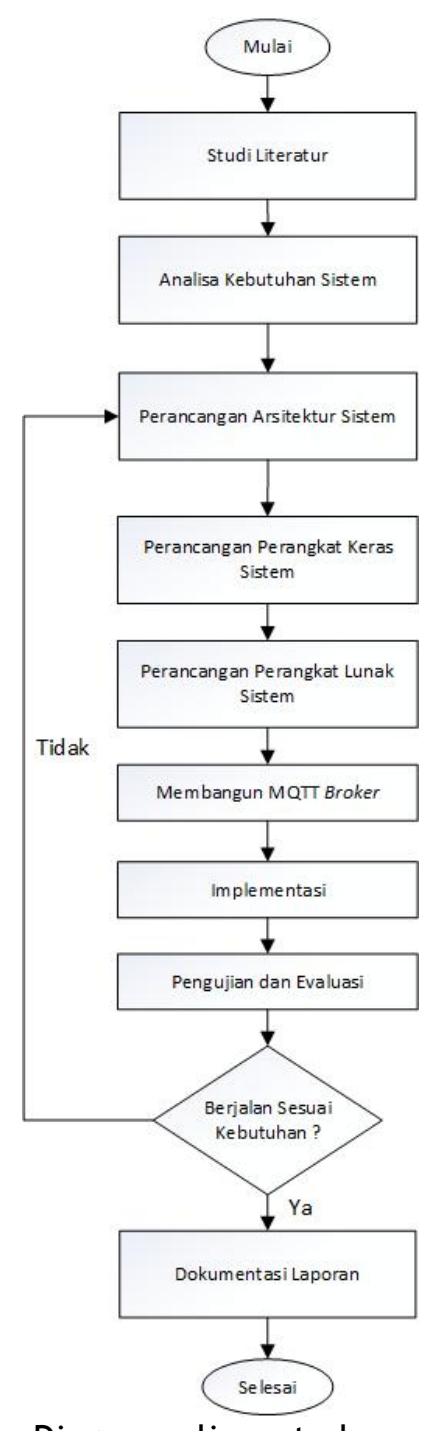

Gambar 1. Diagram alir metode penelitian

\subsection{Perancangan Arsitektur Sistem}

\subsubsection{Arsitektur Sistem}

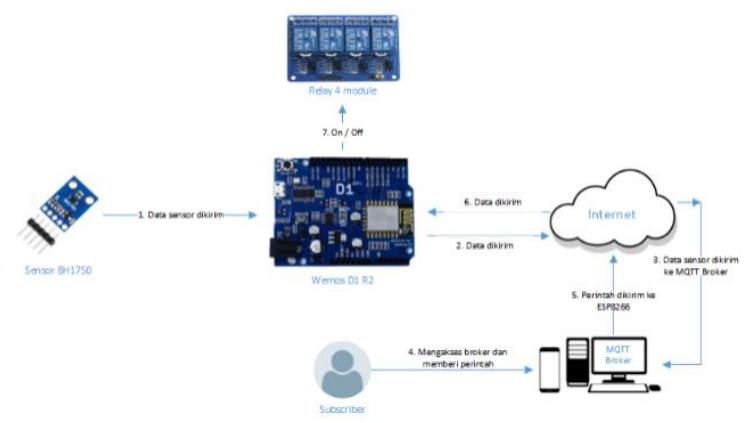

Gambar 2. Arsitektur sistem

3.2.2 Fuzzy Inferensi Sistem

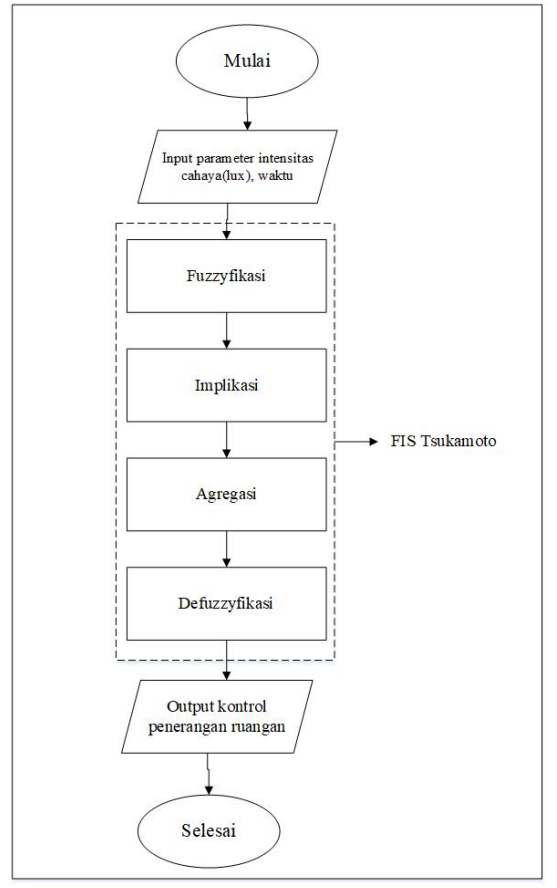

Gambar 3. Diagram alir FIS Tsukamoto Untuk mendapatkan keluaran diperlukan 4 tahapan yaitu:

a. Fuzzyfikasi

Proses fuzzyfikasi pada penelitian ini dilakukan terhadap dua variabel yang ada yaitu intensitas cahaya dan waktu. Berikut merupakan gambaran kurva fungsi keanggotaan yang digunakan pada penelitian ini.

1. Fungsi keanggotaan variabel intensitas cahaya

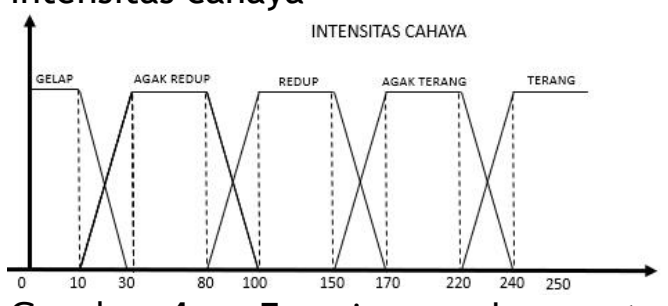

Gambar 4. Fungsi keanggotaan intensitas cahaya

2. Fungsi keanggotaan variabel waktu

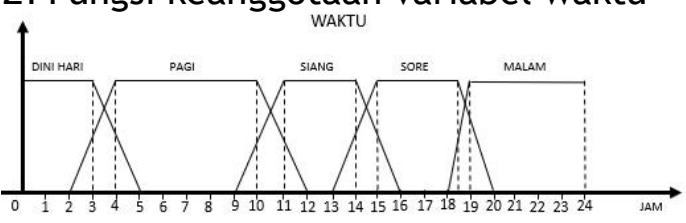

Gambar 5. Fungsi keanggotaan waktu

3. Fungsi keanggotaan kesimpulan kondisi lampu 


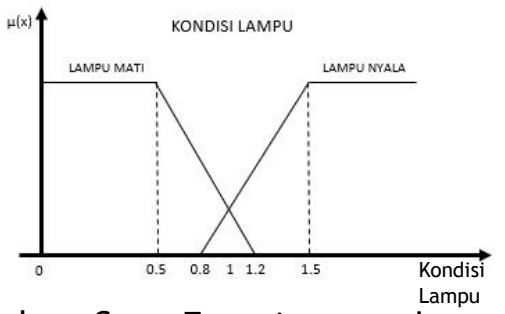

Gambar 6. Fungsi

keanggotaan kondisi lampu

b. Aplikasi Implikasi

c. Agregasi

d. Defuzzyfikasi

e. Contoh Perhitungan

\subsection{Konfigurasi Perangkat Keras Sistem}

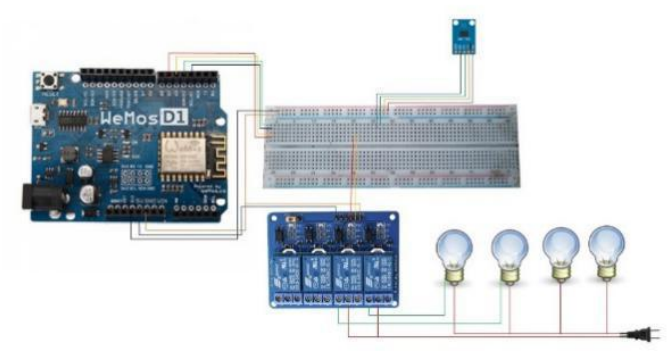

Gambar 7. Rancangan perangkat keras sistem

Perancangan perangkat keras sistem pendukung keputusan penerangan ruangan pada Gambar 4 menggunakan mikrokontroler ESP8266 (Wemos D1 R2) yang dihubungkan dengan sensor dan alat modul modul dengan menggunakan kabel jumper dan bantuan breadboard agar masing-masing modul dan sensor dapat mengakses vcc dan ground pada ESP8266. ESP8266 digunakan sebagai induk dari perangkat keras sistem yang berfungsi untuk mengontrol modul modul dan sensor serta menghubungkan ke server (MQTT Broker). Sensor yang ada digunakan untuk menerima input berdasarkan jenis sensornya, yakni sensor BH1750 digunakan untuk menerima data intensitas cahaya yang ada di dalam ruangan.

Modul yang digunakan juga memiliki peran masing-masing, seperti relay digunakan untuk menghidupkan dan mematikan lampu dengan memberikan aliran listrik terhadap lampu. Dan lampu yang digunakan untuk menambah penerangan di dalam ruangan.

\subsection{Rancangan Perangkat Lunak}

Pada sistem pendukung keputusan penerangan ruangan berbasi loT akan dibangun kontrol aplikasi yang digunakan untuk mengontrol perangkat keras dan aplikasi sistem. Pada penelitian ini juga menggunakan ESP8266 dan mengiplementasikan protokol MQTT yang mana data akan di publish ke broker, adapun perancangan kontrol aplikasi dan perancangan broker sebagai berikut:

\subsubsection{Rancangan Kontrol Aplikasi}

Kontrol aplikasi merupakan aplikasi yang akan dipasangkan pada Wemos D1 R2 R1 dan digunakan untuk mengendalikan sensor dan modul untuk menerima input dan memberikan output. Kontrol aplikasi dibangun menggunakan Bahasa pemrograman C. Rancangan dari kontrol aplikasi dapat dilihat pada Gambar 5.

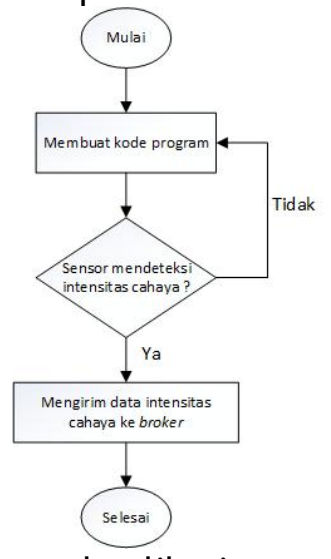

Gambar 8. Kontrol aplikasi

\subsubsection{Rancangan Komunikasi MQTT}

Saat ini banyak broker yang digunakan, salah satunya pada penelitian ini yaitu CloudMQTT. CloudMQTT merupakan server Mosquitto (server yang menggunakan protokol telemetri transport untuk menyediakan layanan pertukaran data loT menggunakan model publish/subscribe atau message queue) yang termanage untuk tujuan komersil dan gratis bagi pengguna non-profit. Selain menerima koneksi dari aplikasi client MQTT, CloudMQTT memiliki jembatan yang memungkinkan untuk terhubung ke server MQTT lain, termasuk instance CloudMQTT lainnya. Sehingga memungkinkan jaringan server MQTT dibangun, dan meneruskan CloudMQTT dari lokasi mana pun ke jaringan lokasi lain, tergantung pada konfigurasi jembatan. Adapun usecase diagram dari sisi pengguna dapat dilihat pada Gambar 6:

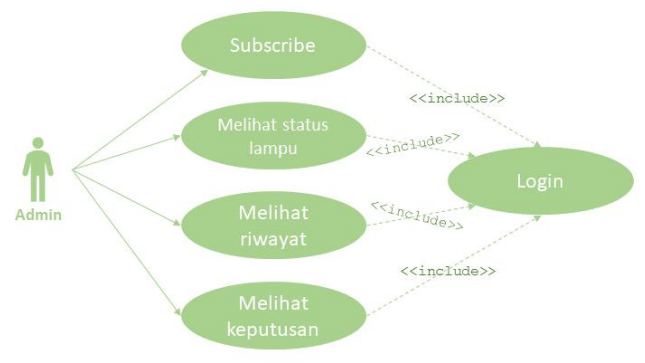

Gambar 9. Usecase diagram komunikasi MQTT

Pada Gambar 6, user dapat melakukan subscribe ke broker, menyalakan dan mematikan 
lampu, melihat status lampu, dan mendapatkan notifikasi sistem aktif atau mati.

\subsubsection{Rancangan Aplikasi Pendukung Keputusan Penerangan Ruangan}

Rancangan aplikasi pendukung keputusan penerangan ruangan merupakan tahap perancangan prototype user interface sistem. Pada tahap ini akan dibuat tampilan dari sistem yang akan dibangun dengan menggunakan android studio. Berikut perancangan aplikasi sistem:

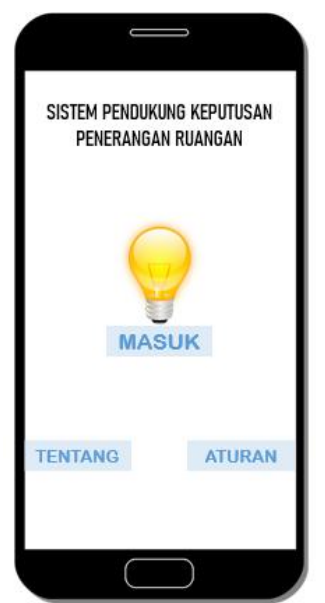

Gambar 10. Rancangan aplikasi pendukung keputusan penerangan ruangan

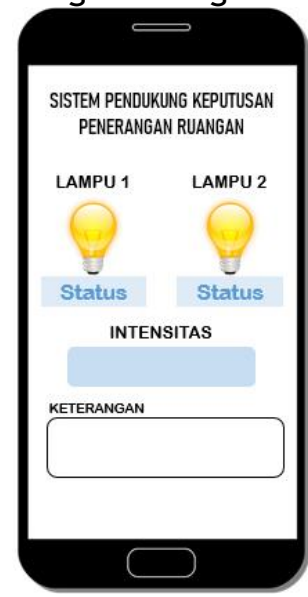

Gambar 11. Rancangan aplikasi pendukung keputusan penerangan ruangan

\section{Hasil dan Pembahasan}

\subsection{Realisasi Sistem}

Pada bab ini, akan membahas hasil dari penelitian yang dilakukan yaitu "Sistem Pendukung Keputusan Penerangan Ruangan Berbasis IOT Menggunakan Protokol MQTT dan Fuzzy Tsukamoto". Realisasi yang dilakukan telah dibuat sesuai dengan perancangan yang dijabarkan pada bab sebelumnya. Pembahasan yang akan dijelaskan meliputi Realisasi penyusunan perangkat keras, Realisasi pmembangunan Control Application, Realisai pembangunan Mobile Application, dan Realisai pembangunan Broker. Selain itu, pada bab ini juga akan dibahas mengenai hasil dari sistem yang telah dibuat berdasarkan perancangan yang ada, melakukan pengujian sistem serta mengevaluasi sistem yang telah berjalan.

\subsubsection{Realisasi Penyusunan Perangkat Keras}

Realisasi penyusunan perangkat keras sistem pendukung keputusan penerangan ruangan dapat dilihat pada tiga gambar berikut:

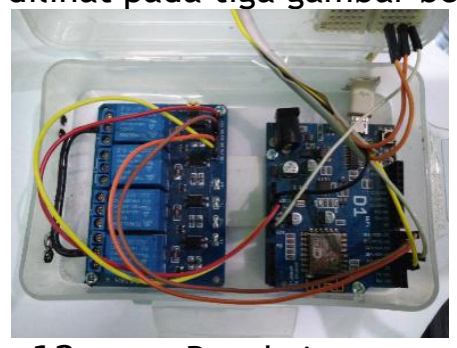

Gambar 12. Rangkaian perangkat keras sistem pendukung keputusan penerangan ruangan

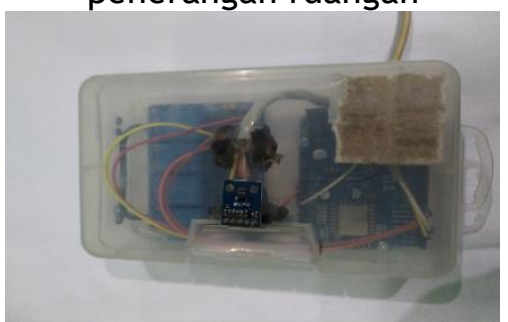

$\begin{array}{llll}\text { Gambar } & 13 . & \text { Rangkaian } & \text { perangkat } \\ \text { keras } & \text { sistem } & \text { pendukung } & \text { keputusan }\end{array}$ penerangan ruangan

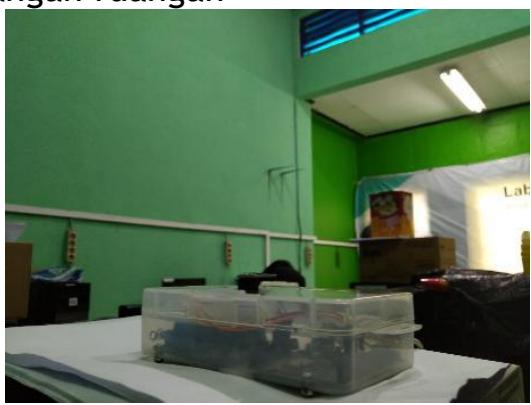

Gambar 14. Rangkaian perangkat keras sistem pendukung keputusan penerangan ruangan

\subsubsection{Realisasi Pembangunan Kontrol Aplikasi}

Dalam realisai pembangunnan control application IDE yang digunakan adalah Arduino IDE dan bahasa yang digunakan adalah bahasa $C$. Untuk membangun control application agar semua modul dan sensor dapat terkoneksi antara yang satu dengan yang lain dan sistem berjalan sesuai dengan yang diinginkan, maka dibuatlah source code yang memiliki alur seperti pada Gambar 15 berikut: 


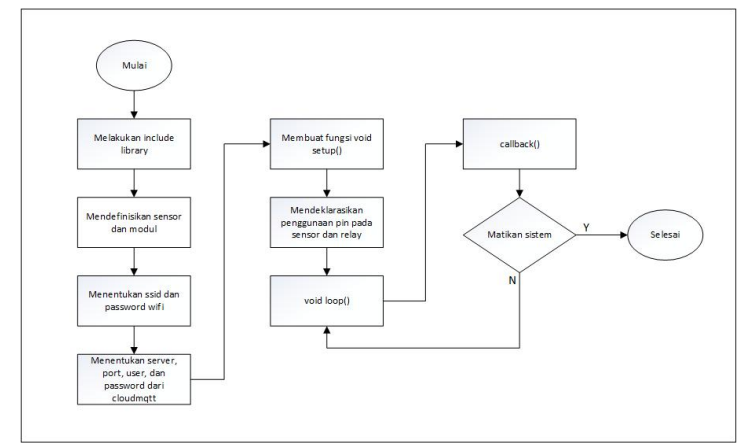

Gambar 15. Alur kerja source code

4.1.3 Realisasi Pembangunan Broker

Pada realisasi pembangunan broker, broker yang digunakan adalah cloudmqtt sebagai tempat penyimpanan data yang di-publish oleh control application sesuai dengan server, port, user, password pada cloudmqtt. Tampilan details dan websocket ui yang terdapat pada cloudmqtt seperti pada Gambar 16 dan Gambar 17 berikut:

$$
\begin{aligned}
& \text { Details } \\
& \text { Instance info }
\end{aligned}
$$

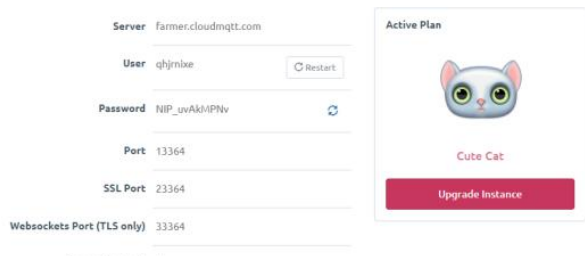

Gambar 16. Instance info broker cloudmqtt

Berdasarkan Gambar 16 terdapat instance info seperti server, user, password, dan port yang dideklarasikan pada control application sehingga dapat terhubung untuk melakukan publish dan subscribe antara control application dengan broker.

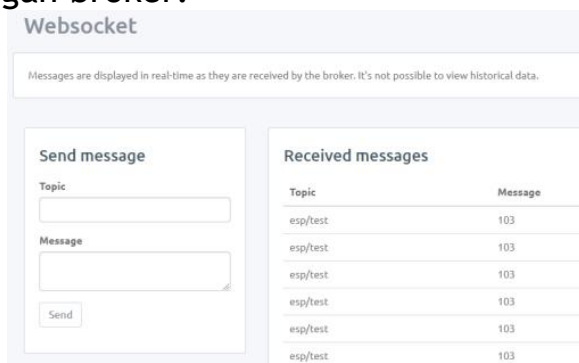

Gambar 17. Broker sistem pendukung keputusan penerangan ruangan

Berdasarkan Gambar 17 terdapat send message yang digunakan untuk melakukan publish ke control application dan receive message yang digunakan untuk menampilkan data yang di-subscribe oleh broker dari control application sesuai dengan topic yang telah dideklarasikan pada control application yaitu esp/test.

\subsubsection{Realisasi Pembangunan Aplikasi Mobile}

Pada realisasi pembangunan aplikasi mobile, software yang digunakan adalah Visual Code Studio dan menggunakan framework flutter serta bahasa pemrograman dart dalam pembuatan kode program. Struktur folder yang terdapat pada Visual Code Studio dapat dilihat pada Gambar 17 berikut:

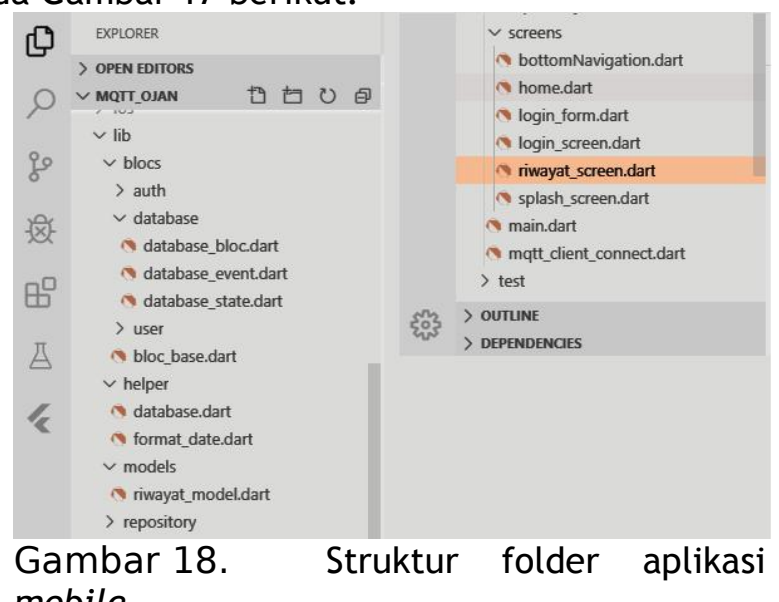
mobile

\subsubsection{Realisasi Pembangunan Sistem Pendukung Keputusan Penerangan Ruangan}

Dalam pembangunan sistem pendukung keputusan berbasis loT menggunakan protocol mqtt dan metode fuzzy tsukamoto, dengan menggunakan bahasa pemrograman dart. Berikut adalah realisasi interface dari sistem pendukung keputusan penerangan ruangan.

\section{A. Halaman Login}
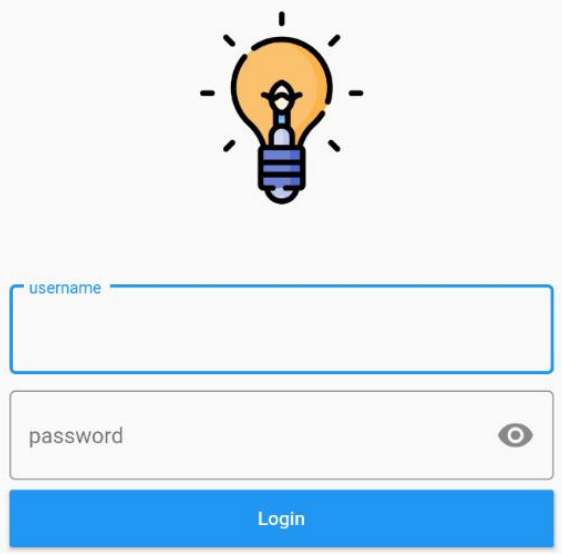

Gambar 19. Tampilan halaman login

B. Halaman Home 


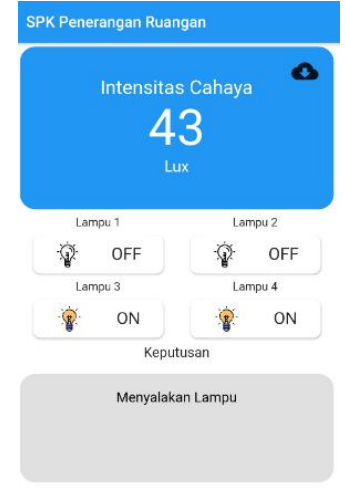

Tampilan halaman home Gambar 20.

\section{Halaman Riwayat}

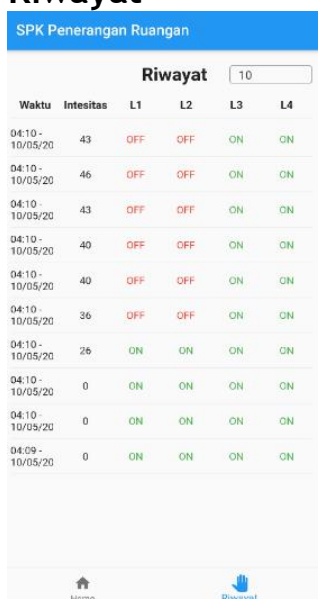

Gambar 21. Tampilan halaman riwayat

\subsection{Pengujian Sistem}

Pengujian sistem pendukung keputusan penerangan ruangan ini dilakukan dengan cara metode pengujian black box yaitu menguji perangkat dari segi spesifikasi fungsional tanpa menguji desain dan kode program. Maksud dari pengujian ini yitu dapat mengetahui apakah fungsi dan keluaran sudah berjalan sesuai yang diharapkan atau tidak. Berikut merupakan hasil pengujian yang telah dilakukan pada sistem pendukung keputudan penerangan ruangan.

\section{Pengujian Sensor BH1750}

Pengujian sensor BH1750 yaitu sensor ditempatkan pada sebuah media dalam ruangan yang dapat terjangkau oleh cahaya. Melakukan pengujian terhadap sensor agar dapat mendeteksi intensitas cahaya dalam ruangan. Pengujian dilakukan dengan beberapa kondisi yaitu lampu ruangan mati dan ventilasi terbuka, lampu menyala dan ventilasi terbuka, lampu mati dan ventilasi tertutup, dan lampu menyala dan ventilasi tertutup. Hasil yang didapatkan memiliki toleransi error sebesar 1,9\% dari alat ukur manual yaitu menggunakan aplikasi Lux Light Meter sebagai nilai sebenarnya. Berdasarkan pengujian yang dilakukan maka didapatkan hasil seperti pada Tabel 1.

Tabel 1 Pengujian sensor $\mathrm{BH} 150$

\begin{tabular}{|c|c|c|c|c|}
\hline $\begin{array}{c}\text { Kondisi } \\
\text { Lampu }\end{array}$ & $\begin{array}{c}\text { Ventilasi } \\
\text { Cahaya }\end{array}$ & $\begin{array}{c}\text { Sensor } \\
\text { BH1750 } \\
\text { (lux) }\end{array}$ & $\begin{array}{c}\text { Lux } \\
\text { Light } \\
\text { Meter }\end{array}$ & Selisih \\
\hline Mati & Terbuka & 173 & 171 & 2 \\
\hline Menyala & Terbuka & 246 & 243 & 3 \\
\hline Mati & Tertutup & 3 & 3 & 0 \\
\hline Menyala & Tertutup & 60 & 57 & 3 \\
\hline
\end{tabular}

\section{Pengujian Relay}

Pengujian relay 4 module ini relay ditempatkan di dalam kotak yang sama dengan mikrokontroler. Melakukan pengujian relay untuk mengetahui relay sudah memberikan output yang sesuai dengan perintah pada mikrokontroler atau tidak. Pengujian dilakukan dengan memberikan cahaya yang berbeda pada sensor BH1750 sehingga mengetahui apakah relay bekerja dengan baik. Kontak poin yang digunakan pada relay yaitu normally open sehingga akan menyala dalam keadaan LOW (0) dan mati dalam keadaan HIGH (1). Berdasarkan pengujian yang dilakukan maka didapatkan hasil seperti pada Tabel 2 . Tabel 2. Pengujian relay

\begin{tabular}{|c|c|c|c|c|}
\hline $\begin{array}{c}\text { Intensitas } \\
\text { Cahaya }\end{array}$ & $\begin{array}{c}\text { Switch } \\
\mathbf{1}\end{array}$ & $\begin{array}{c}\text { Switch } \\
\mathbf{2}\end{array}$ & $\begin{array}{c}\text { Switch } \\
\mathbf{3}\end{array}$ & $\begin{array}{c}\text { Switch } \\
\mathbf{4}\end{array}$ \\
\hline 80 & 0 & 0 & 0 & 0 \\
\hline 230 & 1 & 1 & 1 & 1 \\
\hline 126 & 1 & 0 & 1 & 0 \\
\hline
\end{tabular}

3. Pengujian Keseluruhan Sistem

Pengujian fungsi keseluruhan sistem yaitu sensor ditempatkan pada sebuah bidang di laboratorium sistem cerdas. Melakukan pengujian terhadap sensor yang dilakukan selama 3 hari dengan waktu yang berbeda-beda. Nilai intensitas yang didapatkan dari pengujian sensor digunakan sebagai parameter untuk mendapatkan keputusan kondisi peenerangan ruangan. Perhitungan keputusan menggunakan fuzzy tsukamoto dilakukan secara manual dan menggunakan sistem. Berdasarkan pengujian yang dilakukan, maka didapatkan hasil keputusan seperti pada Gambar 21. 


\begin{tabular}{|c|c|c|c|c|c|}
\hline \multicolumn{2}{|c|}{ Waktu } & \multirow{2}{*}{$\begin{array}{c}\text { Intensitas } \\
\text { (lux) }\end{array}$} & \multirow{2}{*}{$\begin{array}{c}\text { Hasil Fuzzy } \\
\text { Manual }\end{array}$} & \multirow{2}{*}{$\begin{array}{c}\text { Hasil Fuzzy } \\
\text { Sistem }\end{array}$} & \multirow{2}{*}{ Keputusan } \\
\hline Hari & Jam & & & & \\
\hline \multirow{5}{*}{ Hari Ke-1 } & 9:13:40 & 43 & 1,45 & 1,46 & Menyalakan Lampu \\
\hline & 11:32:11 & 76 & 1,38 & 1,38 & Menyalakan Lampu \\
\hline & $13: 14: 19$ & 93 & 0,84 & 0,84 & Menyalakan Lampu \\
\hline & 15:01:38 & 80 & 1,38 & 1,38 & Menyalakan Lampu \\
\hline & $16: 41: 10$ & 64 & 1,5 & 1,5 & Menyalakan Lampu \\
\hline \multirow{5}{*}{ Hari Ke-2 } & 9:00:50 & 42 & 1,5 & 1,5 & Menyalakan Lampu \\
\hline & $11: 26: 17$ & 77 & 1,38 & 1,38 & Menyalakan Lampu \\
\hline & $13: 03: 24$ & 93 & 0,84 & 0,84 & Menyalakan Lampu \\
\hline & $14: 58: 40$ & 82 & 1,28 & 1,28 & Menyalakan Lampu \\
\hline & $16: 34: 14$ & 66 & 1,5 & 1,5 & Menyalakan Lampu \\
\hline \multirow{5}{*}{ Hari Ke-3 } & 9:32:41 & 50 & 1,41 & 1,41 & Menyalakan Lampu \\
\hline & 12:03:11 & 82 & 1,4 & 1,4 & Menyalakan Lampu \\
\hline & $13: 30: 55$ & 92 & 0,9 & 0,9 & Menyalakan Lampu \\
\hline & $15: 01: 54$ & 82 & 1,28 & 1,28 & Menyalakan Lampu \\
\hline & $16: 49: 05$ & 63 & 1,5 & 1,5 & Menyalakan Lampu \\
\hline
\end{tabular}

Gambar 21. Pengujian keseluruhan sistem

Hasil perhitungan yang paling tinggi yaitu hari pertama 1,5 dengan nilai intensitas

$64 l u x$ dan waktu

$16: 41.10$, hari

kedua 1,5 dengan nilai intensitas

42 lux

dan waktu 9:00.50, serta nilai intensitas

66lux dan waktu 16:34.14, hari

ketiga 1,5 dengan nilai intensitas

$42 \operatorname{lux}$

dan waktu 16:49.05. Sedangkan hasil perhitungan yang paling rendah yaitu hari pertama 0,84 dengan nilai intensitas

42 lux dan waktu

13: 14.19 , hari

kedua 0,84 dengan nilai intensitas

93lux

dan waktu 13: 03.24 , dan hari ketiga 0,9

dengan nilai intensitas 92lux dan waktu

13:30.55 . Semakin besar nilai hasil perhitungan yang didapatkan maka keputusan untuk "Menyalakan Lampu" semakin tinggi, sedangkan semakin kecil hasil perhitungan maka keputusan untuk "Mematikan Lampu" semakin tinggi. Seperti pada Gambar 21 terlihat semua keputusan yang didapatkan dari hasil pengujian sistem yaitu "Menyalakan Lampu".

Pada penelitian ini sesuai hasil pengukuran menunjukan dukungan keputusan untuk "Menyalakan Lampu". Hal tersebut dikarenakan tidak terpenuhinya syarat standar cahaya untuk laboratorium. Kedepan perlu dilakukan penelitian lanjutan untuk mengukur bagaimana agar standar intensitas cahaya untuk laboratorium dapat terpenuhi, yaitu dengan menggunakan lampu yang memiliki lumen lebih besar dan menggunakan dimmer untuk menyesuaikan redup atau terangnya lampu.

Berdasarkan hasil pengujian sistem pendukung keputusan penerangan ruangan yang dilakukan pada Gambar 21, hasil perhitungan fuzzy menggunakan perhitungan manual dan perhitungan sistem memiliki nilai yang sama. Contoh perhitungan manual salah satu data pengujian yaitu sebagai berikut:

Gambar 22 merupakan hasil perhitungan secara manual dengan perbandingan hasil dari masukan nilai intensitas cahaya dan waktu sesuai dengan hasil penelitian yaitu intensitas cahaya (76 lux) dan waktu (11:32).
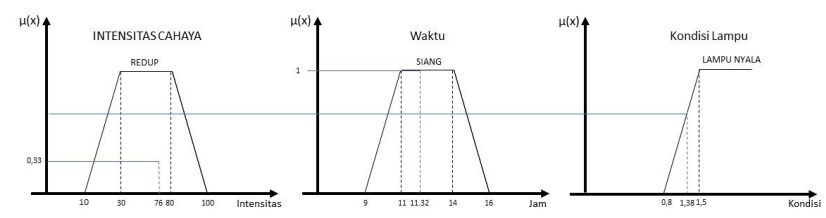

Gambar 22 Pengujian secara manual

Tabel hasil perhitungan secara manual dengan perbandingan hasil dari masukan nilai intensitas dan waktu sesuai hasil penelitian menghasilkan kombinasi aturan fuzzy yaitu intensitas redup $(0,33)$ dan waktu siang (1) dengan hasil lampu nyala $(1,38)$, dapat dilihat pada Tabel 3.

Tabel 3. Hasil perhitungan secara manual

\begin{tabular}{|c|c|c|c|}
\hline Perhitungan & $\begin{array}{c}\text { Intensitas } \\
\text { Cahaya }\end{array}$ & Waktu & Kondisi \\
\hline Manual & $\begin{array}{l}\text { Redup } \\
(0,33)\end{array}$ & $\begin{array}{c}\text { Siang } \\
\text { (1) }\end{array}$ & $\begin{array}{c}\text { Lampu } \\
\text { Nyala } \\
(1,38)\end{array}$ \\
\hline
\end{tabular}

Gambar 23 merupakan hasil perhitungan menggunakan sistem dengan perbandingan hasil dari masukan nilai intensitas cahaya dan waktu sesuai dengan hasil penelitian yaitu intensitas cahaya (76 lux) dan waktu (11:32).

Tabel hasil perhitungan menggunakan sistem dengan perbandingan hasil dari masukan nilai intensitas dan waktu sesuai hasil penelitian menghasilkan kombinasi aturan fuzzy yaitu intensitas redup $(0,33)$ dan waktu siang (1) dengan hasil lampu nyala $(1,38)$, dapat dilihat pada Tabel 4.

Tabel 4. Hasil perhitungan menggunakan sistem 


\begin{tabular}{|c|c|c|c|}
\hline Perhitungan & $\begin{array}{c}\text { Intensitas } \\
\text { Cahaya }\end{array}$ & Waktu & Kondisi \\
\hline \multirow{2}{*}{ Sistem } & $\begin{array}{c}\text { Redup } \\
(0,33)\end{array}$ & $\begin{array}{c}\text { Siang } \\
(1)\end{array}$ & $\begin{array}{c}\text { Lampu } \\
\text { Nyala } \\
(1,38)\end{array}$ \\
\hline
\end{tabular}

4. Pengujian Tambahan

Pengujian tambahan dilakukan pada ruangan yang berbeda dengan ventilasi cahaya yang lebih memadai, pengujian dilakukan dengan waktu satu hari pada jam yang berbeda beda. Hasil pengujian tambahan pada ruangan yang berbeda dapat dilihat pada Gambar 23 berikut:

\begin{tabular}{|c|c|c|c|c|}
\hline Waktu & Intensitas & $\begin{array}{c}\text { Hasil Fuzzy } \\
\text { Manual }\end{array}$ & $\begin{array}{c}\text { Hasil Fuzzy } \\
\text { Sistem }\end{array}$ & Keputusan \\
\hline $12: 00$ & 143 & 0,5 & 0,5 & Matikan Lampu \\
\hline $12: 30$ & 160 & 0,85 & 0,85 & Matikan Lampu \\
\hline $13: 00$ & 176 & 0,5 & 0,5 & Matikan Lampu \\
\hline $13: 30$ & 175 & 0,56 & 0,57 & Matikan Lampu \\
\hline $14: 16$ & 230 & 0,85 & 0,85 & Matikan Lampu \\
\hline $14: 43$ & 113 & 0,95 & 0,96 & Menyalakan Lampu \\
\hline $15: 07$ & 273 & 0,61 & 0,61 & Matikan Lampu \\
\hline $15: 21$ & 123 & 1,33 & 1,33 & Menyalakan Lampu \\
\hline $15: 43$ & 183 & 0,61 & 0,61 & Matikan Lampu \\
\hline $16: 05$ & 86 & 1,20 & 1,20 & Menyalakan Lampu \\
\hline
\end{tabular}

Gambar 23. Hasil pengujian tambahan

Berdasarkan hasil pengujian tambahan sistem pada Tabel 4.6 nilai kondisi terendah yang didapatkan yaitu 0,5 pada jam 12:00 dengan intensitas 143 lux dan jam 13:00 dengan intensitas yaitu 176 lux sehingga memberikan keputusan untuk "Matikan Lampu". Sedangkan nilai kondisi yang tertinggi yaitu 1,33 pada jam 15:21 dengan intensitas 123 sehingga memberikan keputusan untuk "Menyalakan Lampu". Hasil pada pengujian tambahan lebih tinggi nilai intensitasnya dibandingkan dengan hasil pengujian pada Lab. Sistem Cerdas. Hal ini disebabkan oleh pengaruh ventilasi udara pada masing-masing ruangan, seperti pada Lab. Sistem Cerdas ventilasi udara tertutup oleh banner sehingga cahaya dari luar yang menjangkau ruangan kurang maksimal.

Hasil perhitungan secara manual dan sistem pada pengujian tambahan memiliki hasil yang sama, hasil perhitungan dapat dilihat pada Gambar 24 berikut:

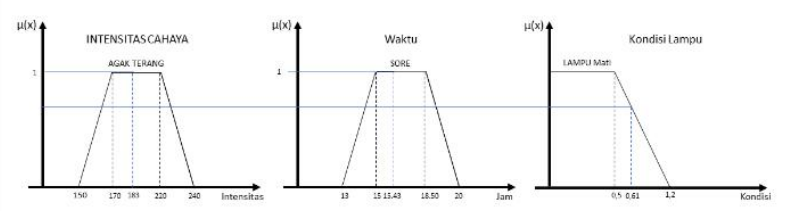

Gambar 24. Hasil perhitungan secara manual dan menggunakan sistem

Gambar 24 merupakan hasil perhitungan secara manual dan menggunakan sistem dengan perbandingan hasil dari masukan nilai intensitas cahaya dan waktu sesuai dengan hasil penelitian yaitu intensitas cahaya (183 lux) dan waktu (15:43).

Tabel hasil perhitungan secara manual dan menggunakan sistem dengan perbandingan hasil dari masukan nilai intensitas dan waktu sesuai hasil penelitian menghasilkan kombinasi aturan fuzzy yaitu intensitas agak terang (1) dan waktu sore (1) dengan hasil lampu mati $(0,61)$, dapat dilihat pada Tabel 5 .

Tabel 5. Hasil perhitungan secara manual dan menggunakan sistem

\begin{tabular}{|c|c|c|c|}
\hline Perhitungan & $\begin{array}{c}\text { Intensitas } \\
\text { Cahaya }\end{array}$ & Waktu & Kondisi \\
\hline $\begin{array}{c}\text { Manual dan } \\
\text { Sistem }\end{array}$ & Agak & Sore & $\begin{array}{c}\text { Lampu } \\
\text { Terang }\end{array}$ \\
& $(1)$ & $(1)$ & $\begin{array}{c}\text { Mati } \\
(0,61)\end{array}$ \\
\hline
\end{tabular}

\section{Kesimpulan}

\section{Kesimpulan dan Saran}

Penerangan ruangan pada Laboratorium Sistem Cerdas belum memenuhi standar dengan nilai hasil pengukuran paling tinggi yaitu 93 lux hasil perhitungan fuzzy yaitu 0,84 dengan keputusan "Menyalakan Lampu". Sedangkan pada ruangan lain dapat memenuhi standar dengan nilai intensitas tertinggi yaitu 273 lux dan hasil perhitungan fuzzy yaitu 0,61 dengan keputusan "Matikan Lampu"

Sensor intensitas cahaya BH1750 dapat mengukur nilai intensitas cahaya dengan toleransi error sebesar 1,9\% dari alat ukur manual Lux Light Meter.

Protokol MQTT lebih efisien digunakan pada sistem pendukung keputusan penerangan ruangan berbasis loT karena data yang disimpan memiliki ukuran kecil dan berupa nilai integer.

Perhitungan pada sistem sudah memiliki hasil yang sama dengan perhitungan secara manual meskipun terdapat sedikit perbedaan pada nilai dibelakang koma (,) hal tersebut karena proses pembulatan pada perhitungan manual dan sistem.

Pada pengujian tambahan terlihat bagaimana sistem dapat memberikan saran yang berbeda sesuai dengan kondisi cahaya dalam ruangan, yaitu "Matikan Lampu" apabila hasil perhitungan fuzzy $<0,95$ berdasarkan masukan berupa intensitas dan waktu. Dan menghasilkan 
keputusan "Menyalakan Lampu" apabila hasil perhitungan fuzzy >= 0,95 dengan masukan intensitas cahaya dan waktu.

\section{Saran}

Pengujian dilakukan di laboratrium atau ruangan lain yang memiliki jendela sebagai perbandingan pasokan cahaya alami di jam masih terdapat matahari.

Menguji pada kasus ruangan lain yang memiliki fungsional dan standar tingkat cahaya yang berbeda seperti ruangan rapat, ruang kelas dan sebagainya.

Membuat sistem untuk memberi saran penambahan tingkat penerangan dan jumlah lampu agar terpenuhi standar fungsional ruangan.

\section{Daftar Pustaka}

[1] N. Azizah, "Manajemen Pencahayaan Alami dan Buatan pada Gedung Pascasarjana UNISMA," vol. 5, no. 4, page. 1-8, 2017.

[2] P. Satwiko, Fisika Bangunan. Yogyakarta: Andi, 2008.

[3] R. P. Pratama, "Rumah Dengan Mini Webserver Avr," page. 1-16, 2017.

[4] I. P. D. S. I Ketut Darminta, I Putu Astawa, "Rancang Bangun Sistem Kontrol Cahaya Lampu Berbasis Mikrokontroler Atmega32," J. Log., vol. 16, no. 2, page. 134-139, 2016.

[5] M. D. Putro and F. D. Kambey, "Sistem Pengaturan Pencahayaan Ruangan Berbasis Android pada Rumah Pintar," J. Nas. Tek. Elektro, vol. 5, no. 3, page. 297, 2018.

[6] Iyuditya and E. Dayanti, "Sistem Pengendali Lampu Ruangan Secara Otomatis Menggunakan PC Berbasis Mikrokontroler Arduino Uno," J. Online ICT STMIK IKMI, vol. 10, no. 2, page. 1-7, 2013. 